\title{
Modeling of creep-fatigue interaction effects on crack growth at elevated temperatures
}

\author{
Gabriel P. Potirniche ${ }^{1 *}$ \\ ${ }^{1}$ Mechanical Engineering Department, University of Idaho, 875 Perimeter Drive MS 0902, Moscow, ID 83844-0902, USA
}

\begin{abstract}
The well-known load frequency effect on creep-fatigue crack growth is explained by the interactions between fatigue and creep loading and is quantified using the concept of plasticityinduced crack closure. It is shown that the hold time during creep loading affects crack growth rates during subsequent fatigue cycles. Longer hold times lead to lower crack-tip opening stresses and faster crack growth rates during fatigue loading. To model the impact of hold time on crack opening stresses during fatigue loading, a strip-yield model was developed for creep-fatigue crack growth. The strip-yield model computes crack-tip opening stresses, which determine the effective stress intensity factor range and crack growth rate during the fatigue portion of each loading cycle. Maximum stress intensity factor is used to compute the crack growth rate during the creep portion of each cycle. The proposed strip-yield model is used to compute creep-fatigue crack growth rates for several structural materials, i.e., an Astroloy, aluminium alloy 2650 and 316 stainless steel. The model predictions of crack growth rates compare well with published experimental data for these alloys. This model achieves reliable predictions of crack growth rates and life prediction on components subjected to creep-fatigue loading at elevated temperatures by considering loading interaction effects.
\end{abstract}

\section{Introduction}

Failure by crack growth during creep-fatigue loading is an important failure mode for structural components in service at elevated temperatures in power plants or in the aerospace industry. Creep-fatigue loading is a combination of a creep portion, in which the load is held constant at a certain level, and a fatigue portion, in which the load fluctuates between minimum and maximum values. The two types of loading can act synergistically on determining how fast cracks grow each creep-fatigue cycle. A common approach is to assume that total crack growth rate is the sum of growth rates during each portion of a loading cycle. Some models neglect the interaction effects of creep and fatigue loads on crack growth rate, while others consider these effects by modeling crack tip damage.

The objective of this paper is two-fold. First, it proposes a modeling approach for the influence of hold time during creep loading on the crack growth rate during subsequent fatigue cycles. Second, predictions of crack growth rates are presented for several alloys commonly used in structural applications at elevated temperatures. The approach presented in this study is denoted as StripYield Model for Creep-Fatigue Crack Growth (SYMCFCG). Creep-fatigue crack growth is predicted using a strip-yield methodology, devised to compute crack growth rates during the fatigue and creep portions of each loading cycle. Strip-yield methodology has been used successfully to predict fatigue crack growth rates in metallic components under constant and variable amplitude loading. This modeling approach is well suited to capture the effects of loading history on fatigue crack growth rates. In the present study, SYM-CFCG is used to capture loading history effects on crack growth by quantifying how creep loading affects crack growth rates during subsequent fatigue cycles.

Strip-yield modeling is a computational approach in which the crack plane, including both crack surface and uncracked ligament in front of the crack tip, is discretized with a certain number of one-dimensional elements of a given length and width. During crack growth under applied loading, new elements are generated with lengths computed according to the mechanics of crack opening and closing.

The proposed SYM-CFCG uses the weight function method to compute relevant fracture mechanics parameters related to crack growth, such as crack surface displacements and plastic and creep zones in front of the crack tip. SYM-CFCG also computes the plastic wake left behind the advancing crack tip and the contact stresses between crack surfaces during unloading. Moreover, SYM-CFCG computes crack-tip driving forces, such as effective stress intensity factor range $\Delta K_{\text {eff }}$, and relevant creep fracture parameters $C^{*}, C(t)$ and $C(t)_{a v g}$. Crack growth rates during fatigue loading are computed using $\Delta K_{\text {eff }}$ and during creep loading using $K_{\max }$ or $C(t)_{\text {avg }}$. Excellent predictions and correlations for several commonly used crack geometries are obtained. The geometries analyzed with SYM-CFCG were: middletension (MT), compact-tension (CT), single-edge notched tension (SENT) and double-edge notched tension (DENT) specimens. Materials considered in these simulations were a nickel-base superalloy, aluminum alloy 2650 and

* Correspondence: gabrielp@,uidaho.edu 
stainless steel 316 stainless. These materials are used in structural applications in power plants and the aerospace industry.

\section{Modeling approach}

\subsection{Crack opening and closing}

Total crack growth rate during a typical creep-fatigue cycle is commonly assumed as the sum of growth rates during loading and holding portions of that cycle. Figure 1 presents a typical creep-fatigue loading scheme used to measure crack growth rates, with the loading cycle as $A$ $B-C-D$ and load hold time $t_{H}$.

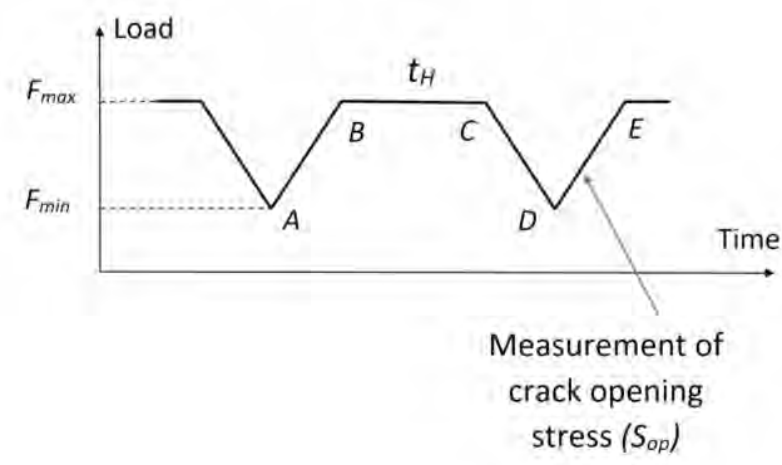

Fig.1. Typical creep-fatigue loading using in crack growth testing.

Crack growth rates during $A-B$ are commonly predicted using $\Delta K_{\text {eff }}$ and during $B-C$ using either $K_{\max }$ or $C(t)$ integral. Crack growth rate during fatigue loading $(A$ $B$ ) is highly dependent on crack-tip opening stress, which is influenced by plasticity-induced crack closure, although other closure mechanisms such as roughnessand oxide-induced crack closure may also play a role at elevated temperatures. In this study, the focus is exclusively on the plasticity-induced crack closure phenomenon.

The core hypothesis of this study, which attempts to explain the influence of creep loading on fatigue crack growth, is that the duration of hold time $t_{H}$ affects the crack-tip opening stress during the subsequent cycle, and implicitly crack growth rate. This is expressed as

$$
\begin{gathered}
\left(\frac{d a}{d N}\right)_{D-E}=f_{1}\left(S_{o p}, \ldots\right), \text { and } \\
\left(S_{o p}\right)_{D-E}=f_{2}\left(t_{H}, \ldots\right)
\end{gathered}
$$

where $d a / d N$ is crack growth rate per cycle, and $f_{l}$ and $f_{2}$ are some unknown functions. The goal of this study is to determine these dependencies represented by $f_{l}$ and $f_{2}$.

The above equation indicates that creep loading affects fatigue crack growth rate through hold time $t_{H}$. In general, for longer hold times $t_{H}$, opening stress $S_{o p}$ decreases, leading to faster crack growth rates during the fatigue portion of that cycle $(D-E)$.

Figure 2 shows an interpretation of how the influence of hold time on the subsequent closing and opening of the crack operates. At maximum load ( point $B$ in Figure 1), the crack is fully open. During hold time $t_{H}(B-C)$, the crack opening displacement increases as a result of stress relaxation and accumulation of creep strains in the near crack-tip region. Longer $t_{H}$ values lead to larger crack-tip opening displacements. For $t_{H}=0$ (i.e., pure fatigue loading) or small hold times, the additional crack opening displacement caused by creep deformation is negligible and, upon unloading, a portion of the crack closes, as illustrated in Figure 2. On the contrary, when $t_{H}$ is large, the additional crack opening displacement caused by creep is significant, and upon unloading, the portion of the crack surface to experience closing at minimum load is shorter than that when $t_{H}=0$ or $t_{H}$ is small. For moderate to long hold times, crack surfaces may not even close at minimum load, and in this case the crack-tip opening stress will match minimum stress. In this situation, effective stress intensity factor range $\Delta K_{\text {eff }}$ is maximized, causing an acceleration of crack growth rate. A caveat to this interpretation is that hold times $t_{H}$ cannot be too large, because the crack opening displacement at $C$ becomes very large, causing significant crack-tip blunting and temporary deceleration of the crack growth rate as the crack tries to re-initiate and propagate in subsequent fatigue cycles. Crack tip blunting due to very large $t_{H}$ is not accounted for in this study.

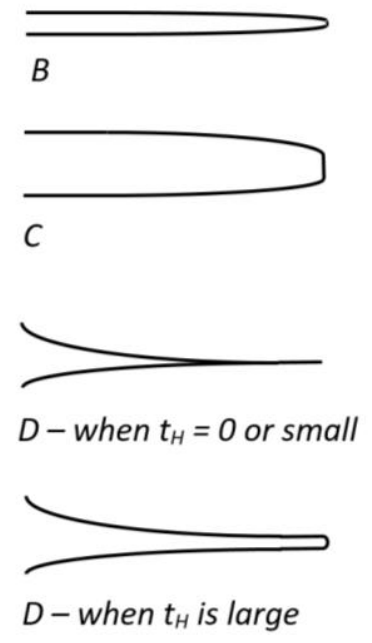

Fig. 2. Crack opening displacements at various points during the creep-fatigue loading cycle illustrated in Figure 1.

These considerations are supported by the finite element simulation results obtained by Sehitoglu and Sun [1] and Ramirez et al. [2]. Both studies showed that opening stresses decrease with longer hold times. Some differences between the two studies exist in terms of the magnitude of hold time impact on opening stresses, and they could be attributed to differences in the model setup and mesh refinement. While Sehitoglu and Sun used a two-dimensional small-scale deformation model and a mesh relatively coarse, Ramirez et al. performed a systematic study employing two- and three-dimensional models for several standard specimens and meshes with a high degree of refinement. Despite their quantitative differences, qualitatively both studies revealed that hold times play a major role in determining crack-tip opening stresses during creep-fatigue loading. 
In addition to the above mentioned finite element efforts, the experimental results obtained by Piard et al. [3] of creep-fatigue crack growth in a nickel-base superalloy showed that longer hold times cause faster crack growth rates during fatigue loading in a creepfatigue cycle. While Piard et al. measured and reported crack growth rates during loading and holding of individual creep-fatigue cycles, they did not measure crack-tip opening stresses. However, their experimental observation of cracks growing faster during loading when the prior hold time was longer could be explained by a decrease of crack-tip opening stresses with longer hold times. In section 3 of this paper, it will be demonstrated that such hypothesis is able to reliably explain their measured crack growth rates.

\subsection{Crack-tip opening stress computation}

The general framework of the proposed SYM-CFCG is similar to the approach published by the author for creep crack growth [4], however a significant improvement has been achieved in this study. While the strip-yield model in study [4] considered only monotonic loading during creep crack growth, currently proposed SYM-CFCG improves on the previous version by considering cyclic loads due to fatigue, and uses a procedure for computing crack-tip opening stresses due to the combined actions of plasticity and creep deformations at the crack tip. In this section the main highlights of this modeling approach are presented.

In an arbitrary specimen subjected to creep-fatigue loading, plastic and creep zones develop near the crack tip [5]. While the plastic zone develops instantaneously under applied load, the creep zone initiates and steadily grows under steady load. Longer $t_{H}$ lead to larger creep zone sizes. During creep zone extension, the normal stress near the crack tip relaxes from its initial flow stress to lower values.

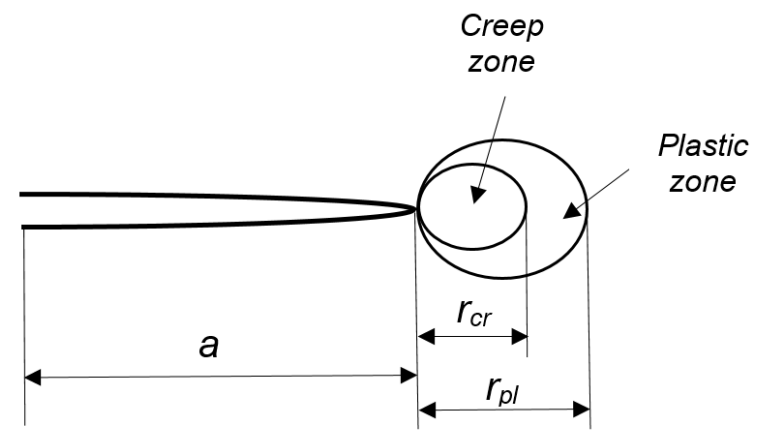

Fig. 3. Extent of plastic and creep deformation zones at the crack tip. Crack length is $a$.

Figure 3 shows the plastic and creep zone regions at the crack tip of a crack with length $a$. The size of plastic zone is $r_{p l}$, and of creep zone is $r_{c r}$. With progression of creep time, creep zone size $r_{c r}$ increases.

Remotely applied stress is denoted as $S$, and it fluctuates between its minimum and maximum values, $S_{\min }$ and $S_{\max }$, respectively. Normal stress in the plastic zone is assumed to have a uniform distribution and equal to $-\alpha \cdot \sigma_{0}$, where $\sigma_{0}$ is flow stress and $\alpha$ constraint factor. Flow stress $\sigma_{0}$ is the average of $S_{y}$ and $S_{u}$, the yield and ultimate strength, respectively. For plane stress $\alpha=1$, and for plane strain $\alpha$ $=3$.

Plastic zone size at the crack tip is computed from the condition that total stress intensity factor at the fictitious crack tip $d=a+r_{p l}$ must be zero

$$
K_{S}+K_{\sigma_{0}}=0
$$

The two stress intensity factors in the equation (2) are computed using the weight function method, as presented by $\mathrm{Wu}$ and Carlsson [6]. All cracked specimens have been analyzed using the $\mathrm{Wu}$ and Carlsson weight functions. For exemple, the stress intensity factors in equation (2) for an MT specimen are the following

$$
\begin{gathered}
K_{S}=\frac{s \sqrt{W}}{\sqrt{\pi d}} \int_{0}^{d} \sum_{i=1}^{3} \beta_{i}(d)\left[1-\left(\frac{x}{d}\right)^{2}\right]^{i-\frac{3}{2}} d x \\
K_{\sigma_{0}}=\frac{-\alpha \sigma_{0} \sqrt{W}}{\sqrt{\pi d}} \int_{a}^{d} \sum_{i=1}^{3} \beta_{i}(d)\left[1-\left(\frac{x}{d}\right)^{2}\right]^{i-\frac{3}{2}} d x
\end{gathered}
$$

where function $\beta$ are defined in [6]. Formulas (3) and (4) are introduced in equation (2). The integrals are computed using a ten point Gauss quadrature, and equation (2) is solved for $r_{p l}$ using the bisection method. Once plastic zone size $r_{p l}$ is computed, it is kept constant throughout the entire creep loading of the particular cycle in which it is calculated.

Before the onset of crack growth, the initial crack plane is discretized using 10 elements for the plastic zone and 5 elements for the crack surface. The width of crack plane elements is the same as those presented in [4,7].

Initial element lengths are the values of crack surface displacements produced by remote loading $S_{\max }$, local stress in the plastic zone $-\alpha \cdot \sigma_{0}$ and stress increment $\Delta \sigma_{c r}$ caused by creep relaxation at the crack tip. The normal stress caused by plastic deformation in the plastic zone is compressive, while stress relaxation caused by creep is tensile. Creep zone size is computed according to a formula presented by Riedel and Rice [8]. Stress relaxation $\Delta \sigma_{c r}$ is considered to occur not only inside the creep zone, but over a larger region ahead of the crack tip, and is computed by multiplying creep zone size with a correction factor, $\rho_{c r} \cdot r_{c r}$. For all simulations $\rho_{c r}$ was chosen as 3.5. Further finite element simulations are planned to gain a better understanding on the extent of the near cracktip region that experiences stress relaxation and redistribution during creep loading.

Riedel [5] showed that for a given creep hold time $t_{H}$, the crack-tip stress in the creep zone relaxes proportionally to $\left(t_{H}\right)^{1 /(1+n)}$, where $n$ is the stress exponent in Norton creep law. Using this result, the stress relaxation due to creep is computed as

$$
\Delta \sigma_{c r}=\alpha \sigma_{0}\left(\frac{t_{0}}{t_{H}}\right)^{\frac{1}{1+n}}
$$

where $t_{0}$ is a time constant accounting for the nonlinear distribution of stresses in the creep zone. For all simulations, this time constant was chosen as $t_{0}=0.001$. 
Element lengths at $S_{\max }$ were computed by superposition of three types of crack surface displacements, i.e., those caused by remote loading, flow stresses in the plastic zone and stress relaxation in the creep zone

$$
L\left(x_{i}\right)=V_{S_{\max }}\left(x_{i}\right)+\sum_{j=1}^{10}\left(-V_{\sigma_{0}}\left(x_{i}, x_{j}\right)+V_{\Delta \sigma_{c r}}\left(x_{i}, x_{j}\right)\right)
$$

where $x_{i}$ is element $i$ coordinate, and $x_{j}$ is the coordinate for element $j$ that causes additional displacement at $i$ because of plasticity and/or creep. Formulas for displacements $V$ in equation (6) are computed using $\mathrm{Wu}$ and Carlsson weight functions.

Upon unloading at $S_{\min }$, contact stresses between the two crack surfaces develop. They are computed following a procedure indicated by Newman [7] and considering the element lengths computed with equation (6). The equation for computing contact stresses at minimum load is

$$
\sum_{j=1}^{10} V_{\sigma_{j}}\left(x_{i}, x_{j}\right)=V_{S_{\min }}\left(x_{i}\right)-L\left(x_{i}\right)
$$

From the above equation, element stresses $\sigma_{j}$ are calculated. Those elements that exceed the flow stress in compression, taken here as $-\sigma_{0}$ are considered yielded in compression, and thus new elements lengths are computed using $S_{\min }$ instead of $S_{\max }$ in equation (6), and the newly computed contact stress distribution $\sigma_{j}$. As indicated by Newman [7], an element cannot exceed a stress of $\alpha \cdot \sigma_{0}$ in tension, or $-\sigma_{0}$ in compression.

After computing contact stresses at minimum load, during the next loading portion, crack-tip opening stress $S_{o p}$ is calculated using a procedure described by Daniewicz et al. [9].

\subsection{Creep-fatigue crack growth laws}

Total crack growth rate per cycle is the sum of the crack growth rates during fatigue and creep loading

$$
\frac{d a}{d N}=\left(\frac{d a}{d N}\right)_{f a t}+\left(\frac{d a}{d N}\right)_{c r}
$$

Fatigue crack growth rates are computed using effective stress intensity factor range $\Delta K_{\text {eff }}$

$$
\left(\frac{d a}{d N}\right)_{f a t}=C \cdot \Delta K_{e f f}^{m}
$$

where $C$ and $m$ are material constants, and $\Delta K_{\text {eff }}=K_{\max }$ $-K_{o p}, K_{\max }$ is maximum stress intensity factor in the cycle, and $K_{o p}$ is opening stress intensity factor. For instance, $K_{o p}$ is calculated using opening stress $S_{o p}$ as follows

$$
K_{o p}=F \cdot S_{o p} \sqrt{\pi a}
$$

where the geometrical factor $F$ depends on the type of testing specimen and crack length.

Creep crack growth rates are computed as

$$
\left(\frac{d a}{d t}\right)_{c r}=C^{\prime} \cdot K_{\max }^{m^{\prime}}
$$

where $C^{\prime}$ and $m$ ' are material constants for the creep crack growth power law. Researchers commonly use either $K_{\max }$ or $C(t)_{\text {avg }}$ integral to correlate crack growth rates for the creep portion of loading cycle. In this study, it was observed that $K_{\max }$ produces in general better results in terms of correlating crack growth rates compared to $C(t)_{\text {avg. }}$. Equation (11) is presented in terms of time rate of crack growth, and it can be transformed to crack growth rate per cycle with the formula

$$
\left(\frac{d a}{d N}\right)_{c r}=\frac{1}{f}\left(\frac{d a}{d t}\right)_{c r}
$$

where $f$ is the test frequency, with $f=1 / t_{H}$, when neglecting the loading and unloading times, which usually occur much faster than creep hold time.

Creep-fatigue interactions are modeled through the influence of load hold time on crack-tip opening stress. Accordingly, SYM-CFCG determines the variation of opening stress on creep loading. Other factors that determine crack-tip opening stresses are specimen type, ratio of applied stress to flow stress and ratio of crack length to specimen width.

\section{Model verification}

Verification of SYM-CFCG was done for several specimens, load ratios and constraint factors. Crack-tip opening stresses were computed and compared with published data in the case of fatigue loading $\left(t_{H}=0\right)$. Figure 4 shows the predicted opening stress from SYMCFCG for MT, SENT and DENT specimens. These predictions are compared with data published by McClung [10] and Newman [11] for MT and SENT specimens.

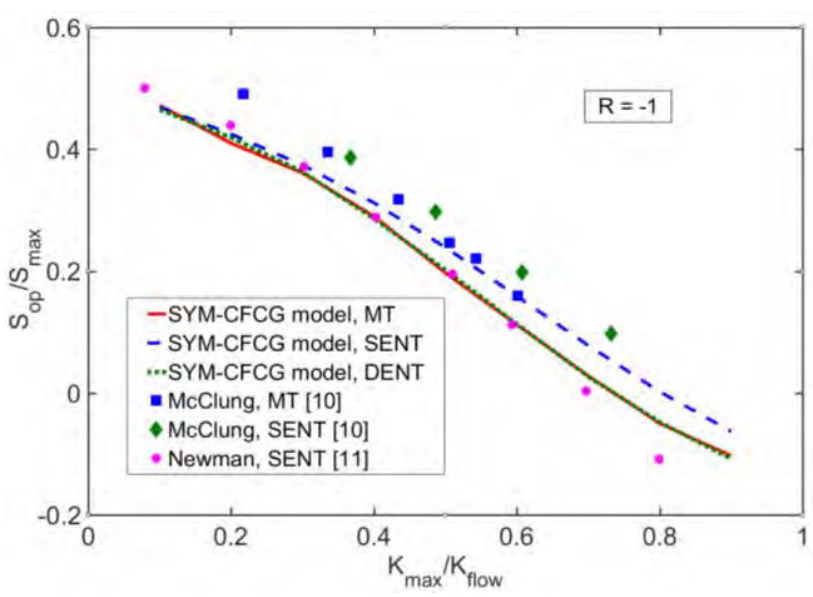

Fig. 4. Comparison of current model predictions (SYM-CFCG) with finite element results ([10]) and strip-yield modeling results ([11]) of crack-tip opening stresses in middle tension (MT), single-edge notched tension (SENT) and double-edge notched tension (DENT) specimens.

The model produces similar opening stresses with results from the McClung and Newman studies for these specimens, at a load ratio of $R=-1$, and for ratios of $S_{\max } / \sigma_{0}$ between 0.1 and 0.9 . Crack-tip opening stress is reported as normalized by maximum applied stress in the cycle. 
Figure 5 shows a comparison of model predictions versus results of the Wang and Blom [12] study for CT specimens. SYM-CFCG predicts similar opening stresses for various load ratios between $R=-1$ and $R=0.8$, and constraint factors of $\alpha=1$ (plane stress), $\alpha=2$ and $\alpha=3$ (plane strain).

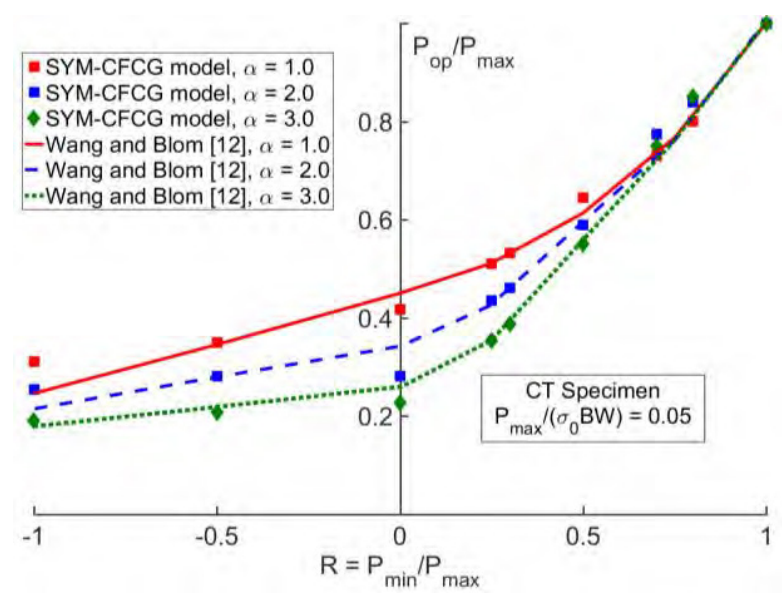

Fig. 5. Comparison of crack-tip opening stress predictions by the current model (SYM-CFCG) with results from literature [12] for the compact tension (CT) specimen.

Maximum applied load was selected according to Wang and Blom simulations as $P_{\max } /\left(\sigma_{0} B W\right)=0.05$, where $B$ is specimen thickness and $W$ specimen width. Agreement between the current model predictions and published literature data is obtained in this case as well.

\section{Results}

In this section, SYM-CFCG predictions are presented and discussed for three materials, a nickel-base superalloy, aluminium alloy 2650 and 316 stainless steels. Experimental data used for comparison with model predictions were taken from published studies. For each case, the material constants, specimen geometry and loading were the same in SYM-CFCG simulations as those in the respective published studies, whenever data was available.

\subsection{Creep-fatigue crack growth in an Astroloy}

The first material for which SYM-CFCG simulation predictions are presented is a nickel-base superalloy, an Astroloy used at high temperatures for turbine engine disks. The experimental study of creep-fatigue crack growth was published by Piard et al. [3], and these simulations replicate their study. The Piard et al. data is perhaps one of the most relevant in terms of highlighting the interaction between creep and fatigue loading on crack growth rates. They measured the influence of hold time $t_{H}$ on crack growth rates during fatigue loading $(d a / d N)_{f a t}$. Piard et al. showed in their experimental measurements that the longer the hold time, the faster cracks grow during the next loading from $F_{\min }$ to $F_{\max }$.

SENT specimens were used in these simulations, similar to those in the Piard et al. tests. Ratio of initial crack length to specimen width was $a / W=0.15$. Ratio of maximum stress to flow stress ratio used was $S_{\max } / \sigma_{0}=$ 0.06 , with $\sigma_{0}=910 \mathrm{MPa}$. Material properties used in this study were: (i) Norton creep constants, $A=2.8 \cdot 10-31 \mathrm{~s}^{-}$ ${ }^{1} \mathrm{MPa}^{-\mathrm{n}}$ and $n=8.5$, (ii) Young's modulus at $750{ }^{\circ} \mathrm{C}$ is $E=$ $160 \mathrm{GPa}$. Material constants used in fatigue crack growth equation (9) were $C=6.47 \cdot 10^{-8}$ and $m=3.1$, with crack growth rate measured in $\mathrm{mm} /$ cycle and $\Delta K$ in $\mathrm{MPa} \cdot \sqrt{\mathrm{m}}$. The crack-tip creep zone correction factor used was $\rho_{c r}=$ 3.5.

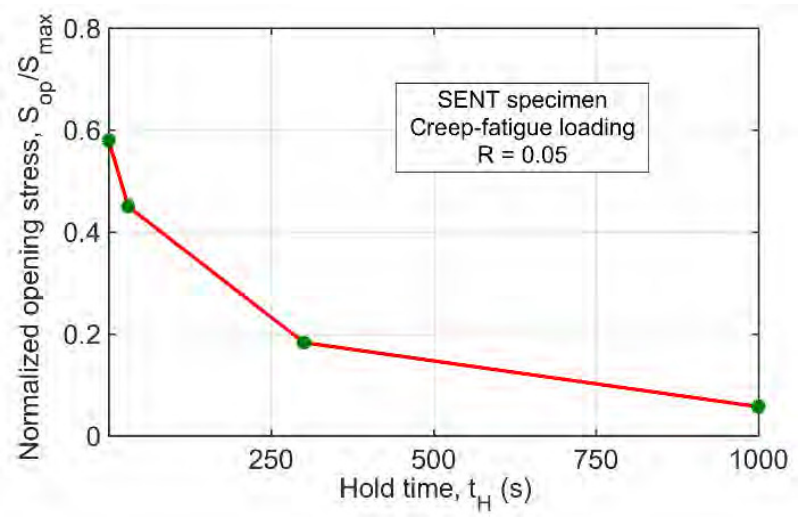

Fig. 6. Computed values of the crack-tip opening stress as a function of creep hold time for the Piard et al. [3] experiments.

Figure 6 shows the computed opening stresses using SYM-CFCG versus hold time for the four different hold times tested by Piard et al., i.e., 0s, 30s, 300s and 1000s. For pure fatigue loading $\left(t_{H}=0 \mathrm{~s}\right)$, the normalized opening stress produced by SYM-CFCG simulations is $S_{o p} / S_{\max }=$ 0.58 . For a hold time of $t_{H}=30 \mathrm{~s}$, the opening stress decreases to $S_{o p} / S_{\max }=0.45$. At a hold time of $t_{H}=300 \mathrm{~s}$, $S_{o p} / S_{\max }=0.18$, while for the largest tested hold time of $t_{H}$ $=1000 \mathrm{~s}$, the opening stress becomes almost equal to the minimum stress in the creep-fatigue cycle, $S_{o p} / S_{\max }=$ 0.057 , whereas $R=\mathrm{S}_{\min } / \mathrm{S}_{\max }=0.05$ ). Crack-tip opening stresses decrease with increasing hold time per cycle, which in turn accelerates the crack growth rate during subsequent fatigue loading, according to equations (9) and (10).

Figure 7 presents the crack growth rates measured by Piard et al. and simulation predictions using SYM-CFCG. The comparison shows that the model predicts crack growth rates well during fatigue loading as a function of hold time. The hold time during creep loading varied from $t_{H}=30 \mathrm{~s}$ to $t_{H}=1000 \mathrm{~s}$. The comparison also shows that for $t_{H}=0$ (i.e. fatigue loading only, and no hold time), predictions match well experimental data for most of $\Delta K$ range.

SYM-CFCG can also predict the initial drop of crack growth rate curve. This decrease in growth rate is explained by the lack of plastic wake as crack starts growing. As the crack becomes longer, a plastic wake of stabilized thickness fully develops behind the crack tip, and crack growth rate stabilizes. Moreover, the model simulations also indicate a minimal drop in initial crack growth rate for tests that involved non-zero hold times. This is caused by diminished plastic wake influence on crack growth rates at longer hold times.

Figure 7 shows that there is some discrepancy between the model predictions and experimental data for $t_{H}=30 \mathrm{~s}$. 
Some of this discrepancy can be explained considering that SYM-CFCG neglects the loading and unloading times, while in Piard et al each lasted 10s. A loading time of 10s may also have some effects on crack growth rates, and this is not taken into account in modeling simulations. The comparison between model simulations and experimental data at $t_{H}=300 \mathrm{~s}$ is excellent, while some discrepancies are observed at $t_{H}=1000 \mathrm{~s}$. The imperfect match of experimental and simulation data at $t_{H}=1000 \mathrm{~s}$ could be attributed in part to some other effects that were not included in the current model, such as severe damage in front of the crack tip at longer hold times.

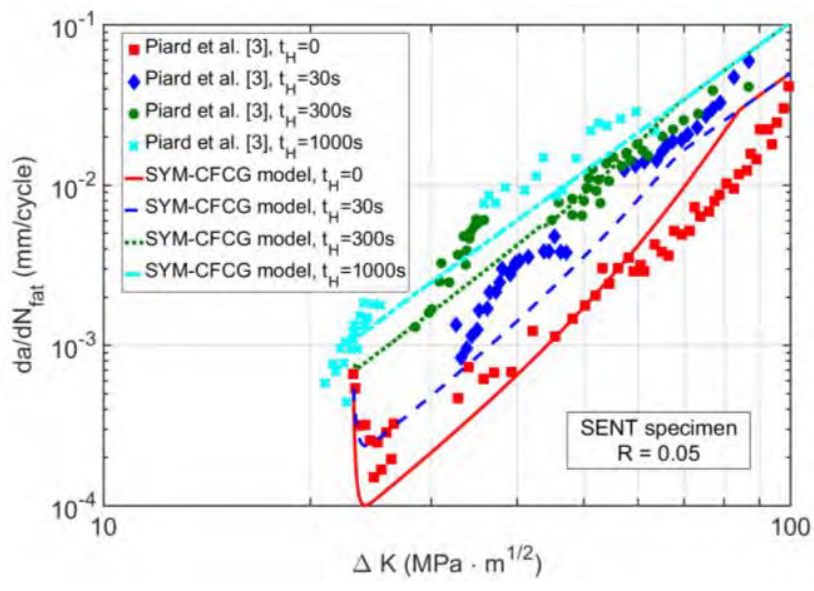

Fig. 7. Comparison of model predictions (SYM-CFCG) with experimental data ([3]) of crack growth rates in a single-edge notch tension (SENT) specimen of Astroloy at $750{ }^{\circ} \mathrm{C}$.

The acceleration of crack growth rate computed by SYM-CFCG approach during loading as a function of hold time is due solely to the decrease in crack closure. It is possible that this effect could be accompanied by some additional damage phenomena that would accelerate the crack growth rate even further, especially for longer hold times.

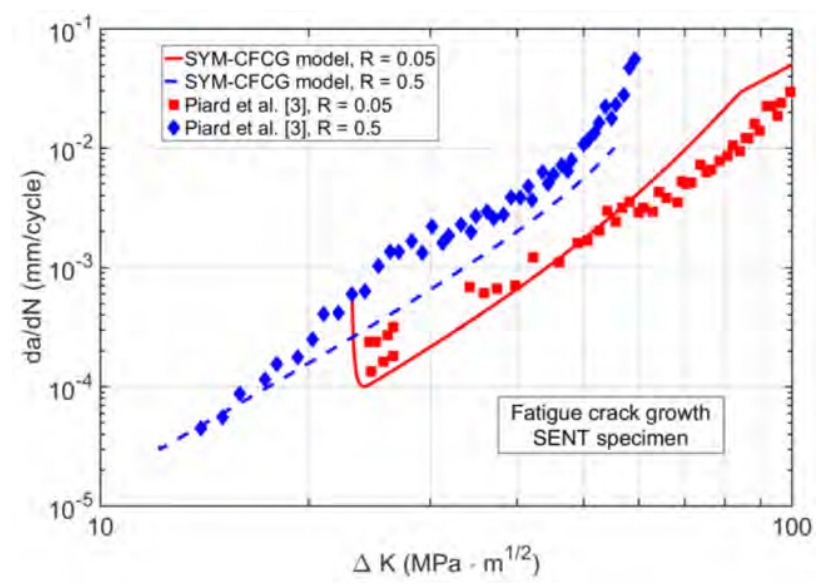

Fig. 8. Comparison between model predictions (SYM-CFCG) and experimental data ([3]) for fatigue crack growth in an Astroloy at $750{ }^{\circ} \mathrm{C}$ and two load ratios R.

Figure 8 shows the SYM-CFCG predictions and Piard et al. experimental results for fatigue crack growth at load ratios of $R=0.05$ and $R=0.5$. These simulations include only fatigue loading and unloading without any hold time.
The model predicts well crack growth rates for both load ratios, based on computed crack-tip opening stresses.

\subsection{Creep-fatigue crack growth in 2650 aluminum alloy}

SYM-CFCG predictions of creep-fatigue crack growth rates in $\mathrm{Cu}-\mathrm{Mg}$ aluminium alloy 2650 were compared with the experimental results of Henaff et al. [13,14]. Two testing temperatures were considered, $130{ }^{\circ} \mathrm{C}$ and $175^{\circ} \mathrm{C}$. $\mathrm{Cu}-\mathrm{Mg}$ aluminium alloys are heavily used in the aerospace industry for fuselage and wing skins. Both simulations and Henaff et al. experiments were performed in CT specimens at a load ratio of $R=0.5$. Material properties used in this study for alloy 2650 at $130{ }^{\circ} \mathrm{C}$ were: $S_{y}=372 \mathrm{MPa}, S_{u t}=412 \mathrm{MPa}, E=68 \mathrm{GPa}, A=8.0 \cdot 10^{-53} \mathrm{~s}^{-}$ ${ }^{1} \mathrm{MPa}^{-n}, n=17.7, C=1.10 \cdot 10^{-10}, m=3.84, C^{\prime}=5.0 \cdot 10^{-9}$, $m^{\prime}=2.35$. At $175^{\circ} \mathrm{C}$ the following material properties were used: $S_{y}=345 \mathrm{MPa}, S_{u t}=365 \mathrm{MPa}, E=65 \mathrm{GPa}, A=$ $4.08 \cdot 10^{-29} \mathrm{~s}^{-1} \mathrm{MPa}^{-n}, n=8.81, C=3.0 \cdot 10^{-10}, m=3.5, C^{\prime}=$ $2.0 \cdot 10^{-8}$, and $m^{\prime}=2.35$. For both temperatures, creep zone correction factor of $\rho_{c r}=3.5$ was used.

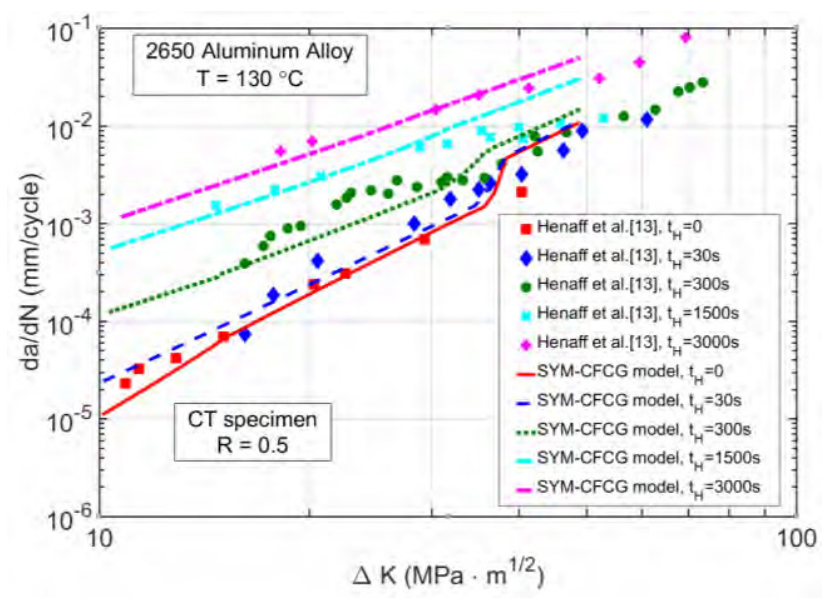

Fig. 9. Comparison between SYM-CFCG simulations and experimental test data ([13]) of creep-fatigue crack growth rates in aluminum alloy 2650 at $130^{\circ} \mathrm{C}$.

Figure 9 shows total crack growth rates for creepfatigue tests performed at $130{ }^{\circ} \mathrm{C}$ in aluminium alloy 2650. The plot shows data for fatigue crack growth $\left(t_{H}=\right.$ 0 ) and creep-fatigue loading with hold times ranging from $30 \mathrm{~s}$ to $3000 \mathrm{~s}$. Figure 10 shows results at $175^{\circ} \mathrm{C}$ for fatigue and creep-fatigue loading with hold time up to $t_{H}=1500 \mathrm{~s}$. Both figures indicate good agreement between the SYMCFCG simulations and experimental data of Henaff et al.

\subsection{Creep-fatigue crack growth in $\mathbf{3 1 6}$ stainless steel}

Predictions of creep-fatigue crack growth using SYMCFCG were also performed for 316 stainless steel. This austenitic stainless steel has vast applicability in structural applications in power plants at elevated temperatures. Two relevant experimental studies in 316 stainless steel at $593{ }^{\circ} \mathrm{C}$ were used to compare with model predictions, namely the works of Michel and Smith [15] and Sadananda and Shahinian [16]. 
The study of Sadananda and Shahinian [16] was performed on 316 stainless steel in $20 \%$ cold worked condition. They used CT specimens with 5\% sidegrooving to maintain an even profile of the crack plane during growth and avoid crack tunneling. Material properties of this material at $593{ }^{\circ} \mathrm{C}$ were: $S_{y}=364 \mathrm{MPa}$, $S_{u t}=617 \mathrm{MPa}, E=153 \mathrm{GPa}, A=7.75 \cdot 10^{-30} \mathrm{~s}^{-1} \mathrm{MPa}^{-n}, n=$ $8.76, C=3.0 \cdot 10^{-5}, m=1.2, C^{\prime}=6.5 \cdot 10^{-4}$ and $m^{\prime}=2.1$.

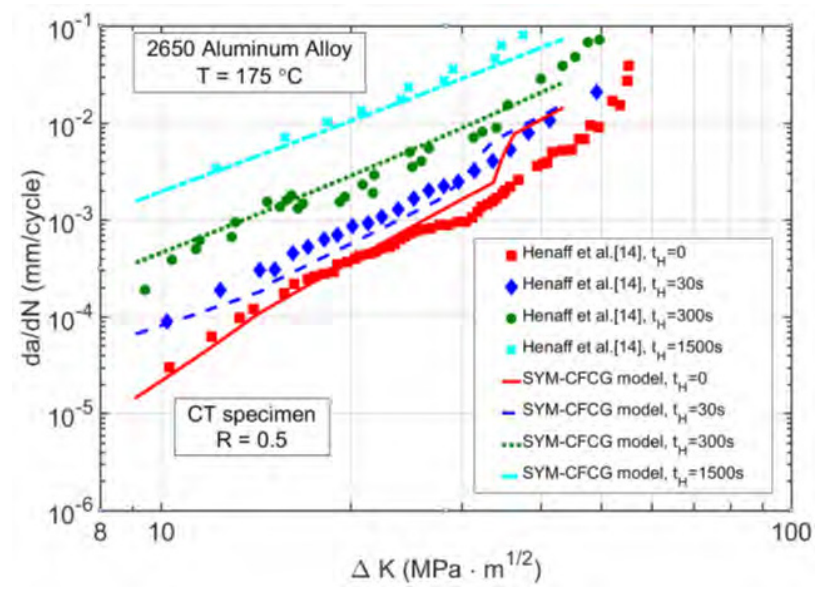

Fig. 10. Comparison between SYM-CFCG simulations and experimental test data $([14])$ of creep-fatigue crack growth rates in aluminum alloy 2650 at $175^{\circ} \mathrm{C}$.

SYM-CFCG simulations were performed in a CT specimen with width $W=50 \mathrm{~mm}$, un-notched thickness $B$ $=12.7 \mathrm{~mm}$, and notched thickness (due to side-grooving) $B_{N}=12.07 \mathrm{~mm}$. Initial crack length was $a_{i}=12.5 \mathrm{~mm}$. Fatigue loading cycle was applied with a maximum load $F_{\max }=13.3 \mathrm{kN}$ and load ratio $R=0.05$. Two tests were performed to replicate the Sadananda and Shahinian experiments. One was a FCG test $\left(t_{H}=0\right)$ and another CFCG test with $t_{H}=60 \mathrm{~s}$. Creep crack zone correction coefficient was $\rho_{c r}=3.5$. In addition to the tests in CT specimens, simulations using SENT specimens were also performed. These simulations were designed to replicate the experiments of Michel and Smith [15]. Their tests were performed on a SENT specimen geometry. SYMCFCG simulations were performed on the same specimen, with width $W=63.5 \mathrm{~mm}$, initial crack length $a_{i}=10 \mathrm{~mm}$, un-notched thickness $B=12.7 \mathrm{~mm}$ and notched thickness $B_{N}=11.43 \mathrm{~mm}$. Michel and Smith also performed experiments on 316 stainless steel in annealed condition. The material properties for the annealed condition at 593 ${ }^{\circ} \mathrm{C}$ were: $S_{y}=148 \mathrm{MPa}, S_{u t}=435 \mathrm{MPa}, E=153 \mathrm{GPa}, A=$ $1.76 \cdot 10^{-36} \mathrm{~s}^{-1} \mathrm{MPa}^{-n}, n=11.83, C=1.6 \cdot 10^{-5}, m=1.5, C^{\prime}=$ $1.5 \cdot 10^{-7}$ and $m^{\prime}=3.7$. The loading conditions were $F_{\max }=$ $47 \mathrm{kN}, R=0, t_{H}=0$ and $t_{H}=60 \mathrm{~s}$.

Figures 11 and 12 show the comparison between SYM-CFCG simulations and experimental data from the two published studies $[15,16]$ in 316 stainless steel at 593 ${ }^{\circ} \mathrm{C}$ in $20 \%$ cold-worked and annealed conditions. Both $t_{H}$ $=0$ and $t_{H}=60 \mathrm{~s}$ simulations show excellent agreement between experiments and simulations. In Figure 11, the data of Sadananda and Shahinian shows some deviation from the modeling predictions for $t_{H}=60 \mathrm{~s}$ loading, however the modeling results match well the experimental data of Michel and Smith [15] for similar hold times.

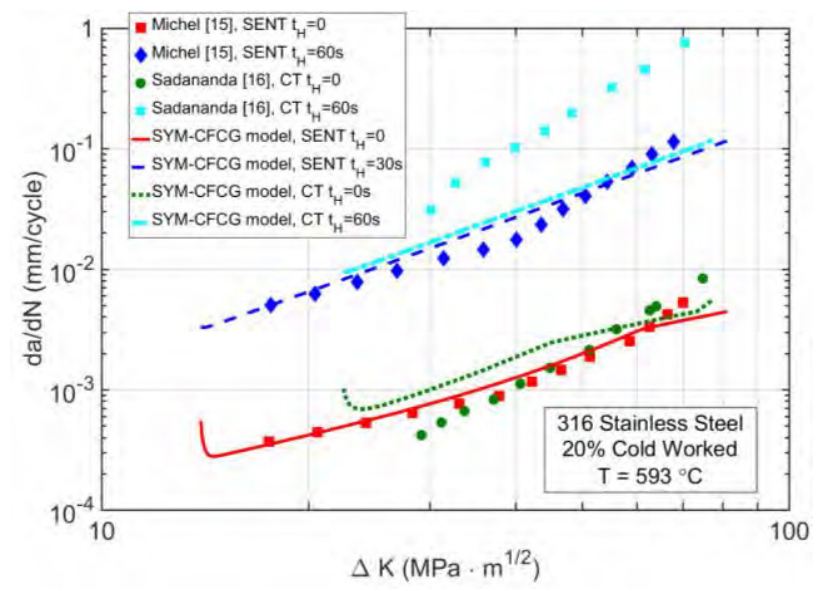

Fig. 11. Comparison between model simulations (SYMCFCG) and experimental results ([15,16]) for creep-fatigue crack growth at $593{ }^{\circ} \mathrm{C}$ in 316 stainless steel $20 \%$ cold worked condition.

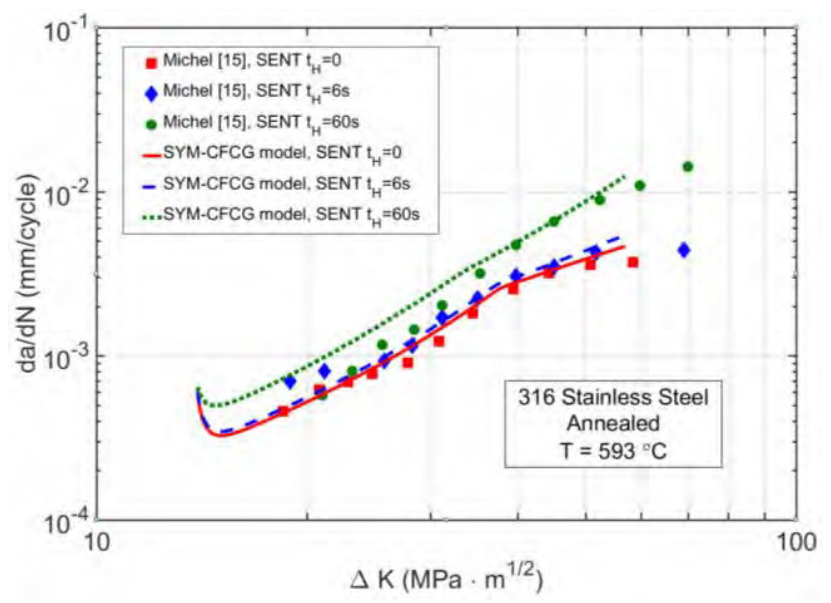

Fig. 12. Comparison between model simulations (SYM-CFCG) and experimental results ([15]) for creep-fatigue crack growth at $593{ }^{\circ} \mathrm{C}$ in 316 stainless steel annealed condition.

\section{Conclusions}

A strip-yield model was developed for creep-fatigue crack growth. The model takes into account both plastic and creep deformations at the crack tip, and the evolution of crack surface displacements during creep-fatigue loading. Load interaction effects on crack growth rates are accounted for by quantifying the influence of creep loading on crack-tip opening stresses due to plasticityinduced crack closure. The model identified that increased creep hold times reduce crack-tip opening stresses, and consequently, increase crack growth rates during fatigue loading. This conclusion is supported by previous finite element modeling results. The model was applied to simulate creep-fatigue crack growth in several structural alloys used at elevated temperatures. Model predictions compared well with published experimental data of crack growth rates in these alloys. The model can be used to perform reliable predictions of creep-fatigue lives in 
structural components used in power plants and the aerospace industry.

The funding support of this work by the U.S. Department of Energy under the Nuclear Energy University Program (Grant DE-NE0008443) work is gratefully acknowledged.

\section{References}

1. H. Sehitoglu, W. Sun, Eng Fract Mech 33, 3 (1989)

2. J. Ramirez, G.P. Potirniche, H. Pugesek, N. Shaber, M. Taylor, R. Stephens, I. Charit., 12th International Fatigue Congress (2018) (to be published)

3. A. Piard, G. Gamby, C.Carbou, J. Mendez, Eng Fr Mech, Eng Fract Mech 71 (2004)

4. G.P. Potirniche, Fatigue and Fracture Mechanics: 38th Volume, STP1546 (2012)

5. H. Riedel, Fracture at High Temperatures (SpringerVerlag, 1986)

6. X.-R. Wu and A. J. Carlsson, Weight Functions and Stress Intensity Factor Solutions (Pergamon Press, 1991)

7. J.C. Newman, Jr., Design of Fatigue and Fracture Resistant Structures, ASTM STP 761 (1982)

8. H. Riedel, J.R. Rice, Fracture Mechanics: Twelfth Conference, ASTM STP 700 (1980)

9. S.R. Daniewicz, J.A. Colins, D.R. Houser, Fatigue 16 (1994)

10. R.M. McClung, Fatigue Fract. Engng Mater. Struct. 17, 8 (1994)

11. J.C. Newman, Jr., Fatigue 02: The Eight International Fatigue Congress (2002)

12. G.S. Wang, A.F. Blom, Eng Fract Mech 40, 4 (1991)

13. G. Henaff, F. Menan, G. Odemer, Eng Fract Mech 77 (2010)

14. G. Henaff, G. Odemer, G. Benoit, E. Koffi, B. Journet Int J Fatigue 31 (2009)

15. D.J. Michel, H.H. Smith, ASME-MPC Symposium on Creep-Fatigue Interaction, ASME (1976)

16. K Sadananda, P. Shahinian, Metall. Trans. A, 11A (1980) 